\title{
Plastic versus metal stents for inoperable gallbladder cancer with hilar biliary obstruction: the jury is still out
}

\author{
Ashish Kumar Jha, Praveen Jha, Sharad Kumar Jha, Ravi Keshari \\ Indira Gandhi Institute of Medical Sciences, Patna, India
}

Abstract

In unresectable malignant hilar obstruction, adequate biliary drainage can be achieved with endoscopic placement of plastic or metal stents. Stent patency and patient survival may differ, depending on the primary disease, disease progression and stent type. Metal and plastic stents were compared in patients with malignant hilar strictures in several studies, but these studies mainly included patients who had cholangiocarcinoma, without taking into consideration potential differences in the invasion properties of tumor cells, histological differentiation and the biological behavior of different tumors. Gallbladder cancer (GBC) is the most common malignancy of the biliary tract, especially in the Indian subcontinent and Latin America. About half the patients with GBC present with jaundice, which usually means the tumor is inoperable. Palliative endoscopic stenting remains the first-line treatment of unresectable GBC with biliary obstruction. Primary disease progression is faster in GBC compared to cholangiocarcinoma. There is a paucity of data on the selection of stents for inoperable GBC with hilar biliary obstruction. This review focuses on the published literature related to the selection of stents for unresectable GBC with hilar obstruction.

Keywords Gallbladder cancer, malignant hilar stricture, stent, metal, plastic

Ann Gastroenterol 2020; 33 (6): 1-8

\section{Introduction}

Malignant bile duct obstruction can be caused by a wide range of tumors, the most common being pancreatic adenocarcinoma in the western world and gallbladder cancer (GBC) in the Indian subcontinent [1-3]. It also may result from cholangiocarcinoma, ampullary cancers, metastatic lesions, other pancreatic tumors, and malignant lymphadenopathy. GBC is the most common malignancy of the biliary tract. The incidence of GBC varies globally. The age-standardized incidence (per 100,000) of GBC for females (2.4) is higher than that for males (2.2) [4]. The incidence (per 100,000) in the United States of America and Western Europe is lower than the worldwide rate, being 1.4 among women and 0.8 among men. The incidence (per 100,000) of GBC is high in many parts of the world, including South and East Asia-North

Department of Gastroenterology, Indira Gandhi Institute of Medical Sciences, Patna, India

Conflict of Interest: None

Correspondence to: Ashish Kumar Jha, MBBS, MD, DM, Associate Professor, Department of Gastroenterology, Indira Gandhi Institute of Medical Sciences, Sheikhpura, Patna 800014, India,

e-mail: ashishjhabn@yahoo.co.in

Received 24 May 2020; accepted 4 August 2020;

published online 12 October 2020

DOI: https://doi.org/10.20524/aog.2020.0548
India (10.0-22.0), South Pakistan (11), Bangladesh (7.3), Nepal (7.3), Thailand (9.0), Republic of Korea (8.4) and Japan (7)and Latin America-Bolivia (15.1), Chile (11.7) and Peru (6.0) $[5,6]$. GBC is endemic across the Indo-Gangetic belt of India [7]. About half the patients with GBC present with jaundice, which usually means that the tumor is inoperable. Palliative biliary drainage remains the first-line treatment of unresectable GBC with biliary obstruction [6].

In unresectable malignant hilar obstruction, adequate biliary drainage can be achieved with endoscopic placement of plastic or metal stents. Stent patency may differ depending on the primary disease, disease progression and stent type. Metal and plastic stents were compared in patients with malignant hilar strictures (MHS) in several studies, but these studies mainly included patients with cholangiocarcinoma. Primary disease progression is faster in GBC compared to cholangiocarcinoma. There is a paucity of data regarding the selection of stents for endoscopic drainage of inoperable GBC with hilar biliary obstruction. Here, we analyze the existing data on endoscopic palliation in patients with hilar stricture due to unresectable GBC. This review focuses on the selection of stents for endoscopic drainage of unresectable GBC with hilar obstruction.

\section{Poor prognosis of GBC}

Most GBCs are discovered incidentally at the time of cholecystectomy. Because they are frequently at an advanced 
stage at the time of diagnosis, only around 10\% of gallbladder tumors are resectable. Tumor progression and metastasis are very common in operated cases of GBCs $[8,9]$. Most GBC patients present late and have either locally advanced or metastatic disease with an extremely poor prognosis. Overall mean survival is about 6 months. The epidemiology of biliary tract cancer was described in a recent population-based cohort study ( $\mathrm{n}=3133$ ) using the Ontario Cancer Registry. The overall incidence of biliary tract cancer increased by $1.6 \%$ per year over the last decade, whereas the incidence of GBC remained unchanged. The median life expectancy was longest for extrahepatic cholangiocarcinoma (11.3 months) and shortest for intrahepatic cholangiocarcinoma (6.2 months). The median life expectancy of GBC patients was 6.4 months, with improvement noted over the study period: 5.1 months (1994$1999)$ vs. 6.0 months (2000-2005) vs. 8.6 months (2006-2012); $\mathrm{P}<0.001$ [10]. In contrast, a Swedish cohort study conducted over a period of 15 years showed no significant improvement in the overall survival of GBC patients: 4.7 months (2000-20004) vs. 4.8 months (2005-2009) vs. 6.1 months (2010-2014) [11]. Non-specific clinical symptoms often delay the diagnosis of GBC, contributing to a poor outcome. The absence of a serosal layer adjacent to the liver is another factor responsible for metastatic progression and the dismal prognosis [6].

\section{Palliative biliary drainage for MHS: an overview}

Approximately half the patients with GBC present with jaundice, which usually implies that the tumor is unresectable [12]. Treatment options for MHS consist mainly of palliative management aimed at relieving jaundice, treating cholangitis and improving quality of life. Definite indications for palliative biliary drainage include cholangitis and intractable pruritus, but is often also offered for deep jaundice and abdominal pain. The indication for biliary drainage for reduction in serum bilirubin in the absence of cholangitis and intractable pruritus is debatable [13-16].

The 3 available methods of palliation of obstructive jaundice in MHS are endoscopic stenting, percutaneous transhepatic biliary drainage (PTBD), and surgical bypass. Palliative endoscopic stenting remains the first-line treatment of MHS. Adequate biliary drainage can be achieved with endoscopic placement of plastic or metal stents. Endoscopic stenting is certainly preferred in Bismuth type I and II malignant hilar strictures [3,14-18]. The optimal route of drainage is controversial in Bismuth type III and IV MHS [13,19-23]. In Bismuth type III and IV MHS, better biliary drainage may be achieved with fewer infective complications via the percutaneous rather than the endoscopic route. However, the disadvantages of PTBD are inconvenience to the patient, external loss of bile, and dislodgment of the PTBD tube. Saluja et al showed that PTBD was better than endoscopic plastic stenting in type II and III hilar strictures caused by GBC [22]. In this study, a staged technique was used for the PTBD arm, which limits comparability. Poor technical success (81\%), as well as high rates of cholangitis (48\%) and stent occlusion
(39\%), were noted in the endoscopic plastic stenting arm, unlike other studies $[17,18]$. The choice between endoscopic or percutaneous drainage is usually based on local expertise [17]. Endoscopic stenting is performed for palliation of Bismuth type III hilar strictures, especially in centers with the most expertise for endoscopic biliary drainage. PTBD is usually preferred over endoscopic stenting in Bismuth type IV hilar strictures [13,14,22,23]. Biliary drainage in Bismuth type III hilar strictures is performed by an interventional radiologist in centers where the technical expertise for endoscopic biliary drainage is not available, and in patients where the endoscopic method has failed $[13,21]$. In a patient with cholangitis and poor general condition urgent percutaneous drainage is required as a temporary measure; endoscopic drainage can be performed at a later stage [13-16] (Fig. 1).

Endoscopic biliary drainage of MHS can be associated with variable clinical success and a high complication rate [24,25]. The following measures improve clinical success and safety: pre-endoscopic retrograde cholangiopancreatography (ERCP) assessment of biliary anatomy and hepatic volume distribution on cross-sectional imaging; magnetic resonance cholangiopancreatography (MRCP)-guided ERCP to avoid contrast opacification of multiple ducts; use of MRCP or aircholangiogram for selective access of duct; drainage of about $50 \%$ of liver (or more) to achieve adequate palliation; and avoiding cannulation of atrophic sectors ( $<30 \%$ drainage) [13-16,26,27]. An attempt should be made to drain all opacified ducts after inadvertent contrast injection into more than one duct, and all blocked ducts in patients with cholangitis [24].

ERCP and stenting may sometimes be technically difficult in the presence of tight malignant strictures, or distorted duodenal anatomy, surgically altered anatomy and gastric outlet obstruction. Endoscopic ultrasound (EUS)guided biliary drainage and stenting have emerged as an alternative rescue procedure to percutaneous drainage in

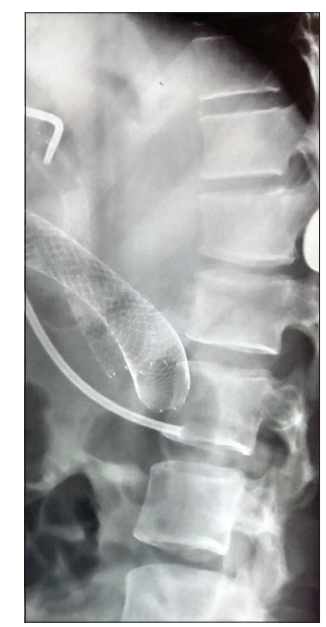

Figure $1 \mathrm{X}$-ray images of the percutaneous transhepatic biliary drainage (PTBD) tube, biliary self-expanding metal stent (SEMS), and duodenal SEMS. Temporary percutaneous biliary drainage was done in an unstable patient of gallbladder cancer with partial gastric outlet obstruction, obstructive jaundice and cholangitis. Endoscopic biliary and duodenal metal stent placement were done 5 days after PTBD 
these patients. Techniques of EUS-guided biliary drainage include EUS-guided choledochoduodenostomy, EUSguided choledochogastrostomy (Fig. 2), EUS-guided hepaticoduodenostomy, EUS-guided hepaticogastrostomy (Fig. 3), the bridging method, and combined endoscopic ultrasound-guided hepaticogastrostomy and transpapillary
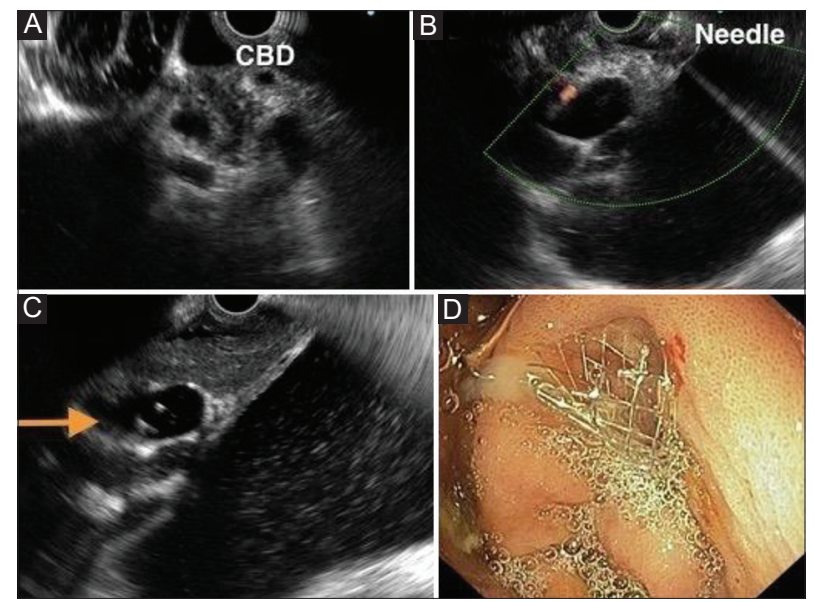

Figure 2 Images of the EUS-guided choledochogastrostomy after failed ERCP (due to duodenal infiltration) in a patient of obstructive jaundice and cholangitis caused by GBC with distal biliary stricture (A: EUS image of dilated CBD; B: Biliary access was achieved with a 19-G FNA needle; C: EUS image of deployed SEMS and D: Endoscopic image of deployed SEMS)

EUS, endoscopic ultrasound; ERCP, endoscopic retrograde cholangiopancreatography; GBC, gallbladder cancer; $C B D$, common bile duct; FNA, fine-needle aspiration; SEMS, self-expanding metal stent

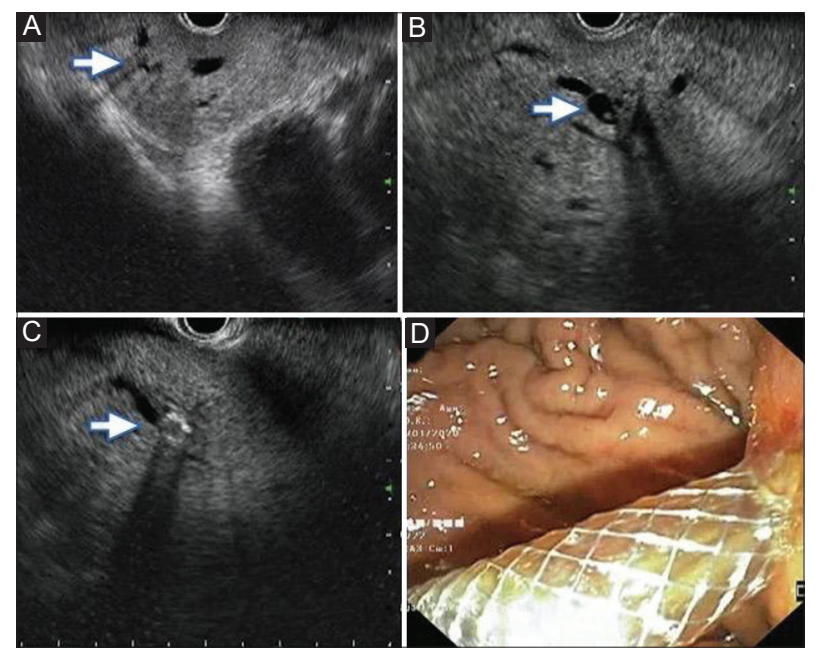

Figure 3 Images of the EUS-guided hepaticogastrostomy after failed ERCP (due to pyloro-duodenal infiltration) in a patient of obstructive jaundice and cholangitis caused by GBC with hilar stricture (A: EUS image of dilated left intrahepatic ducts; B: Selective access to the segment 3 duct was achieved with a 19-G FNA needle; C: EUS image of deployed SEMS and D: Endoscopic image of deployed SEMS)

EUS, endoscopic ultrasound; ERCP, endoscopic retrograde cholangiopancreatography; GBC, gallbladder cancer; FNA, fine-needle aspiration; SEMS, self-expanding metal stentA stenting. The overall technical success rate, clinical success rate and complication rate are around $98 \%, 77 \%$ and $8 \%$, respectively $[28,29]$.

GBC can present with gastroduodenal obstruction, usually treated with endoscopic gastroduodenal stent placement. Endoscopic biliary drainage is difficult in patients with gastroduodenal obstruction. If the duodenoscope fails to negotiate the gastroduodenal obstruction, percutaneous placement of a stent prior to the gastroduodenal stenting is warranted. EUS-guided biliary drainage is an alternative rescue procedure to PTBD in these patients. In a patient with partial gastroduodenal obstruction, endoscopic biliary stenting should be performed before gastroduodenal stenting (Fig. 1). Surgical bypass is mainly performed for intraoperative diagnosis of an unresectable tumor [13-18].

\section{Plastic vs. metal stents for unresectable GBC with hilar biliary obstruction}

Stent patency is an important factor in determining the quality of life, symptomatic relief and cost of therapy [30]. There is still a lack of clear consensus on the relative merits of plastic vs. metal stents and single vs. multiple stents. In the absence of unambiguous consensus, the choice of stent for endoscopic palliation of MHS depends on several conditions, such as the volume of liver drainage, life expectancy, expertise of the endoscopist, and cost issues in the case of low-income and uninsured patients [17,21,26,31-34].

In comparison to plastic stents, metal stents have a larger diameter with a lower risk of stent occlusion. Metal stents are more cost-effective than plastic biliary stents if the patient's remaining life expectancy is longer than 4-6 months. In general, therefore, uncovered metal stents are preferred over plastic stents for the management of malignant biliary obstruction. This is true if expected survival is $>4-6$ months, particularly in the presence of impending duodenal obstruction and recurrent plastic stent blockage. Studies of patients with malignant biliary obstruction have revealed that if the cost of a self-expanding metal stent (SEMS) is more than half the ERCP cost, then initial placement of a plastic stent is more costeffective in patients with expected survival $<4$ months $[32,33]$. In one study, an approximate cost analysis was performed for GBC patients $(n=59)$ undergoing treatment with metal or plastic biliary stenting [17]. The initial intervention cost and the overall cost were higher in the SEMS group compared to the plastic stent group $(\mathrm{P}<0.001)$ [17]. Plastic stenting is indicated for temporary biliary drainage in patients with a potentially resectable GBC. Placement of a plastic stent is also indicated for gallbladder drainage (percutaneous or endoscopic) in a patient with severe cholecystitis due to cystic duct obstruction by a GBC [35]. Stent patency may differ depending on the primary disease, disease progression, tumor expansion beyond the stent and stent type [32,33,36-38]. There is a paucity of data on the selection of stents (plastic vs. metal) for endoscopic palliation of inoperable GBC with hilar biliary stricture $[17,34,37]$. 
Metal and plastic stents have been compared in malignant distal biliary obstruction as well as hilar strictures. The superiority of metal stenting over plastic stent placement in malignant distal biliary obstruction has been shown in several studies. One meta-analysis involved 24 studies (2436 patients) and compared plastic and metal stenting for malignant distal biliary obstruction. The overall success rate and complications were similar in both groups, but placement of metal stents was associated with a significantly reduced risk of recurrent biliary obstruction at 4 months, or prior to death or end of study [31]. In a multicenter prospective observational cohort study, 1-month adverse outcomes were compared in plastic stenting and metal stenting groups in patients with hilar tumors [25]. The rate of adverse outcomes was significantly lower in the SEMS group than in the plastic stent group (11.8\% vs. $39.3 \%$ ) [25]. Metal and plastic stents were compared in patients with MHS in different studies, but these studies mainly included patients with cholangiocarcinoma, without taking into consideration potential differences in invasion properties of tumor cells, histological differentiation and the biological behavior of different tumors $[25,39,40]$. Cholangiocarcinoma typically causes intrinsic biliary obstruction by intraductal growth. However, the hilar biliary obstruction caused by GBC and metastatic cancers is more often an extrinsic mass effect. The median survival duration of patients with inoperable GBC and metastatic cancers is shorter (6 months or less) compared to patients with cholangiocarcinoma (6 months or more) treated with biliary drainage $[3,17,39]$. In one study, the median survival for patients with cholangiocarcinoma, gallbladder carcinoma and metastatic carcinoma was 179 , 104 and 89 days, respectively [39]. Hence, further studies are required to elucidate the relationship between tumor type and stent patency.

The stent patency, complications, reintervention rate and the overall survival time appeared to be comparable between a SEMS group and a plastic stent group in patients who had inoperable GBC with hilar stricture [17]. In a randomized controlled trial, Mukai et al compared SEMS and plastic stents in patients with MHS caused by cholangiocarcinoma, metastatic tumor, GBC, and cholangiocellular carcinoma [34]. The 6-month patency rate was significantly higher in the SEMS group than in the plastic stent group ( $81 \%$ vs. $20 \%$; $\mathrm{P}=0.001$ ); however, there was no significant difference in the overall survival time between the plastic stent and SEMS groups $(\mathrm{P}=0.28)$. The median follow-up period was 220 days in the SEMS group and 189 days in the plastic stent group. All patients died before the final date of the follow-up period [34]. In a recent retrospective study, plastic stenting was compared with metal stenting in unresectable GBC patients $(n=59)$ with jaundice [17]. The therapeutic success rate and the median stent patency were $93 \%$ and 119 days (95\% confidence interval [CI] 68.0-169.9 days) in the SEMS group vs. $93.5 \%$ and 93 days (95\%CI 82.1-103.9 days) in the plastic stent group. Cholangitis occurred in $32.1 \%$ of patients in the SEMS group vs. $38.7 \%$ of patients in the plastic stent group. Stent malfunctions were noted in $64.3 \%$ of patients in the SEMS group vs. $67.7 \%$ of patients in the plastic stent group. Median life expectancy was
112.0 days (95\%CI 92.5-131.4 days) in the SEMS group vs. 118.0 days (95\%CI 95.7-140.2 days) in the plastic stent group. There were no significant differences between the two groups in the clinical success, cholangitis rate, stent patency, stent malfunctions, total hospital stay or cumulative survival [17]. In contrast to the finding in one previously published study that SEMS had a longer stent patency, the median stent patency was comparable for both groups [34]. In another recent retrospective study by Miura et al, risk factors for recurrent biliary obstruction and stent patency were calculated in 104 patients with MHS treated with endoscopic placement of SEMS [36]. Median SEMS patency time and median survival time in patients with GBC were 231 and 147 days, respectively. Of the 12 patients with GBC, 6 (50\%) developed recurrent biliary obstruction and 6 (50\%) died without developing recurrent biliary obstruction. The patients with GBC had a higher risk of recurrent biliary obstruction (hazard ratio 8.18, 95\%CI 2.41-26.83) and shorter stent patency durations than those with cholangiocarcinoma $(n=82)$. During follow up, $82 \%$ patients expired because of progression of their primary malignancy without suffering biliary obstruction [36].

MHS due to GBC are at very high risk of recurrent biliary obstruction after the placement of metal or plastic stents. We were able to find the details of 200 patients with GBC who had hilar biliary strictures treated with biliary stenting. The study details and clinical outcomes of endoscopic palliation in patients with GBC are summarized in Table 1. The results of these studies showed that the GBC with hilar strictures fare very badly, with a high cholangitis rate and poor survival, regardless of the stent type (plastic or metal) and the number of stents (unilateral or bilateral) used. Most stents remain patent longer than the survival time in patients with MHS due to unresectable GBC $[3,17,36,41,42]$. In contrast, Huibregtse et al showed longer overall survival (161 days) of GBC patients compared to biliary stent clogging time (145 days). However, among 64 patients with malignant biliary strictures due to unresectable GBC, only 15 (24\%) had hilar strictures [18]. Patients who have unresectable GBC with hilar strictures and present for endoscopic palliation mostly die before stent occlusion [3,36]. The patients with GBC in these studies were at a very advanced stage, which is usually the case in daily practice [43]. Apart from stent occlusion, rapid progression of primary tumor, severe malnutrition, cachexia, sepsis and peritoneal carcinomatosis are the causes of death in patients with advance GBC.

\section{Unilateral vs. bilateral stenting}

Data regarding the use of unilateral vs. bilateral stenting for MHS are controversial [15]. De Palma et al showed a higher rate of successful stent insertion $(88.6 \%$ vs. $76.9 \%$; $\mathrm{P}=0.041)$ and a lower complication rate $(8.8 \%$ vs. $16.6 \%$; $\mathrm{P}=0.013)$ in their unilateral stenting group compared to the bilateral drainage group [39]. Among 157 patients with MHS, 20\% had strictures due to GBC. Chang et al showed that MHS ( $\mathrm{n}=141)$ fared very badly, with a high cholangitis rate $(32 \%)$ and high mortality (30\%), if unilateral stenting was performed after 
Table 1 Plastic vs. metal stents in patients with gallbladder cancer (GBC) and hilar strictures: summary of important research studies

\begin{tabular}{|c|c|c|c|c|c|c|c|c|c|}
\hline Study & Study design & $\begin{array}{l}\text { Total } \\
\text { cases }\end{array}$ & $\begin{array}{l}\mathrm{GBC} \\
(\mathrm{n})\end{array}$ & Stent type & Stent patency & $\begin{array}{c}\text { Overall } \\
\text { survival (d) }\end{array}$ & $\begin{array}{l}\text { Survival } \\
\text { GBC (d) }\end{array}$ & $\begin{array}{c}\text { Stent } \\
\text { occlusion (\%) }\end{array}$ & $\begin{array}{c}\text { Cholangitis } \\
\text { (\%) }\end{array}$ \\
\hline $\begin{array}{l}\text { Huibregtse } \\
\text { et al (1987) } \\
{[18]}\end{array}$ & $\begin{array}{l}\text { Prospective, } \\
\text { uncontrolled }\end{array}$ & 64 & $\begin{array}{c}64 \\
(\text { Hilar } \\
15)\end{array}$ & $\begin{array}{l}\text { Plastic stent } \\
(\mathrm{UL}=54 \\
\mathrm{BL}=5)\end{array}$ & $145 \mathrm{~d}$ & 161 & 161 & 25.4 & 12.5 \\
\hline (Hilar-15) & $\begin{array}{l}\text { Plastic stent } \\
(\mathrm{UL}=54 ; \mathrm{BL}=5)\end{array}$ & $145 \mathrm{~d}$ & 161 & 161 & 25.4 & 12.5 & & & \\
\hline $\begin{array}{l}\text { Wagner } \\
\text { et al (1993) } \\
{[37]}\end{array}$ & RCT & 20 & 5 & $\begin{array}{l}\text { SEMS }(n=11) \\
\text { vs. PSG }(n=9) \\
(\mathrm{UL}, \mathrm{BL})\end{array}$ & $\begin{array}{l}\text { No difference in } \\
\text { patency }(P>0.05)\end{array}$ & - & - & $\begin{array}{c}18 \text { (SEMS) } \\
\text { vs. } 50 \text { (PSG) } \\
(\mathrm{P}=0.180)\end{array}$ & $\begin{array}{l}9 \text { (SEMS) } \\
\quad \text { vs. } 33 \\
\text { (PSG) } \\
(\mathrm{P}=0.220)\end{array}$ \\
\hline $\begin{array}{l}\text { Vij et al } \\
\text { (1996) [3] }\end{array}$ & $\begin{array}{l}\text { Prospective, } \\
\text { uncontrolled }\end{array}$ & 32 & 32 & $\begin{array}{l}\text { Plastic stent } \\
\text { (UL) }\end{array}$ & NA & 154 & 154 & 12.5 & 11 \\
\hline $\begin{array}{l}\text { De Palma } \\
\text { et al (2003) } \\
{[41]}\end{array}$ & $\begin{array}{l}\text { Prospective, } \\
\text { uncontrolled }\end{array}$ & 61 & 10 & SEMS (UL) & $169 \mathrm{~d}$ & 140 & 104 & 26.1 & 21.2 \\
\hline $\begin{array}{l}\text { Freeman } \\
\text { et al }(2003) \\
{[38]}\end{array}$ & $\begin{array}{l}\text { Prospective, } \\
\text { uncontrolled }\end{array}$ & 35 & 5 & SEMS (UL) & 5.4 months & NA & NA & NA & 0 \\
\hline $\begin{array}{l}\text { Saluja } \\
\text { et al (2008) } \\
{[22]}\end{array}$ & $\begin{array}{l}\text { RCT (PTBD } \\
\text { vs. ES) }\end{array}$ & 27 & 27 & $\begin{array}{l}\text { Plastic stent } \\
\text { (UL) }\end{array}$ & $91 \mathrm{~d}$ & 60 & 60 & 39 & 48 \\
\hline $\begin{array}{l}\text { Naitoh } \\
\text { et al (2009) } \\
{[42]}\end{array}$ & Retrospective & 46 & 22 & $\begin{array}{l}\text { SEMS } \\
\text { (UL vs. BL) }\end{array}$ & $\begin{array}{l}\text { Overall, } 210 \mathrm{~d} \\
(\mathrm{UL}) \text { vs. } 488 \mathrm{~d}(\mathrm{BL}) \\
(\mathrm{P}=0.009) .[\mathrm{GBC} \\
\text { patients-P>0.05] }\end{array}$ & $\begin{array}{c}166(\mathrm{UL}) \\
\text { vs. } 205(\mathrm{BL}) \\
(\mathrm{P}=0.559)\end{array}$ & NA & $\begin{array}{c}59(\mathrm{UL}) \\
\text { vs. } 23(\mathrm{BL}) \\
(\mathrm{P}=0.020)\end{array}$ & $\begin{array}{c}0 \text { (UL) vs. } \\
15(\mathrm{BL}) \\
(\mathrm{P}>0.05)\end{array}$ \\
\hline $\begin{array}{l}\text { Mukai } \\
\text { et al. } \\
(2013)[34]\end{array}$ & RCT & 60 & 13 & $\begin{array}{l}\text { SEMS }(\mathrm{n}=30) \\
\text { vs. PSG } \\
(\mathrm{n}=30) \\
(\mathrm{UL}, \mathrm{BL})\end{array}$ & $\begin{array}{l}\text { 6-months patency } \\
\text { rate in the SEMS vs. } \\
\text { PSG ( } 81 \% \text { vs. } 20 \% \text {; } \\
\mathrm{P}=0.001)\end{array}$ & $\begin{array}{c}220(\text { SEMS }) \\
\text { vs. } 189(\mathrm{PSG}) \\
(\mathrm{P}=0.283)\end{array}$ & NA & $\begin{array}{c}40 \text { (SEMS) } \\
\text { vs. } 70 \text { (PSG) } \\
(\mathrm{P}=0.018)\end{array}$ & NA \\
\hline $\begin{array}{l}\text { Miura } \\
\text { et al (2016) } \\
{[36]}\end{array}$ & Retrospective & 104 & 12 & $\begin{array}{l}\text { SEMS (UL, } \\
\text { BL) }\end{array}$ & $231 \mathrm{~d}$ in $\mathrm{GBC}$ & 281 & 147 & 33.7 & 28 \\
\hline $\begin{array}{l}\text { Gao et al } \\
(2017) \\
{[17]}\end{array}$ & Retrospective & 59 & 59 & $\begin{array}{l}\text { SEMS }(\mathrm{n}=28) \\
\text { vs. PSG } \\
(\mathrm{n}=31) \\
(\mathrm{UL}, \mathrm{BL})\end{array}$ & $\begin{array}{l}119 \mathrm{~d} \text { (SEMS) vs. } 93 \\
\mathrm{~d}(\mathrm{PSG})(\mathrm{P}=0.363)\end{array}$ & $\begin{array}{c}112(\text { SEMS }) \\
\text { vs. } 118(\mathrm{PSG}) \\
(\mathrm{P}=0.861)\end{array}$ & $\begin{array}{l}112 \text { (SEMS) } \\
\text { vs. } 118 \\
\text { (PSG) } \\
(\mathrm{P}=0.861)\end{array}$ & $\begin{array}{c}64(\text { SEMS }) \\
\text { vs. } 68 \text { (PSG) } \\
(\mathrm{P}=0.791)\end{array}$ & $\begin{array}{c}32 \text { (SEMS) } \\
\text { vs. } 39 \\
\text { (PSG) } \\
(\mathrm{P}=0.599)\end{array}$ \\
\hline
\end{tabular}

SEMS, self-expanding metal stent; PSG, plastic stent group; UL, unilateral; BL, bilateral; RCT, randomized controlled trial; $d$, days; PTBD, percutaneous transhepatic biliary drainage; ES, endoscopic stenting; NA, not available

opacification of both sides of the liver, but their data included only $13(9.21 \%)$ GBC patients [24]. Study details and clinical outcomes of unilateral vs. bilateral stents placement in GBC patients with MHS are summarized in Table 2 (plastic stents) and Table 3 (metal stents).

Studies comparing unilateral vs. bilateral stenting in GBC are limited. Most published studies revealed easier stent placement, significantly easier reinterventions and comparable stent patency and safety in unilateral stenting groups compared to bilateral stenting groups $[24,34,39,42,44-46]$. A recent metaanalysis revealed comparable efficacy and safety of unilateral and bilateral metallic stenting in patients with unresectable MHS. Among 911 patients with MHS, 17\% of patients had stricture due to GBC. Technical success was significantly higher in the unilateral group compared to the bilateral group ( $97 \%$ vs.
89\%; $\mathrm{P}=0.003)$. Clinical success rate ( $98 \%$ vs. $94 \% ; \mathrm{P}=0.48)$ and complications were comparable between the 2 groups [47]. In a retrospective study by Naitoh et al, comparison of endoscopic unilateral and bilateral biliary metal stenting was performed in patients with MHS [42]. In most of their 46 patients, the etiology of hilar obstruction was either GBC (22 cases) or cholangiocarcinoma (15 cases). Cumulative stent patency was better in bilateral compared to unilateral biliary drainage $(\mathrm{P}=0.009)$ in patients with cholangiocarcinoma, whereas there were no inter-group differences for GBC. It is worth mentioning that the cumulative survival did not differ significantly between the groups: 166 (unilateral) vs. 205 days (bilateral); $\mathrm{P}=0.55$ [42]. The larger tumor volume and aggressive biological behavior of GBC may be responsible for the early occlusion of a metal stent by tumor overgrowth or ingrowth. 

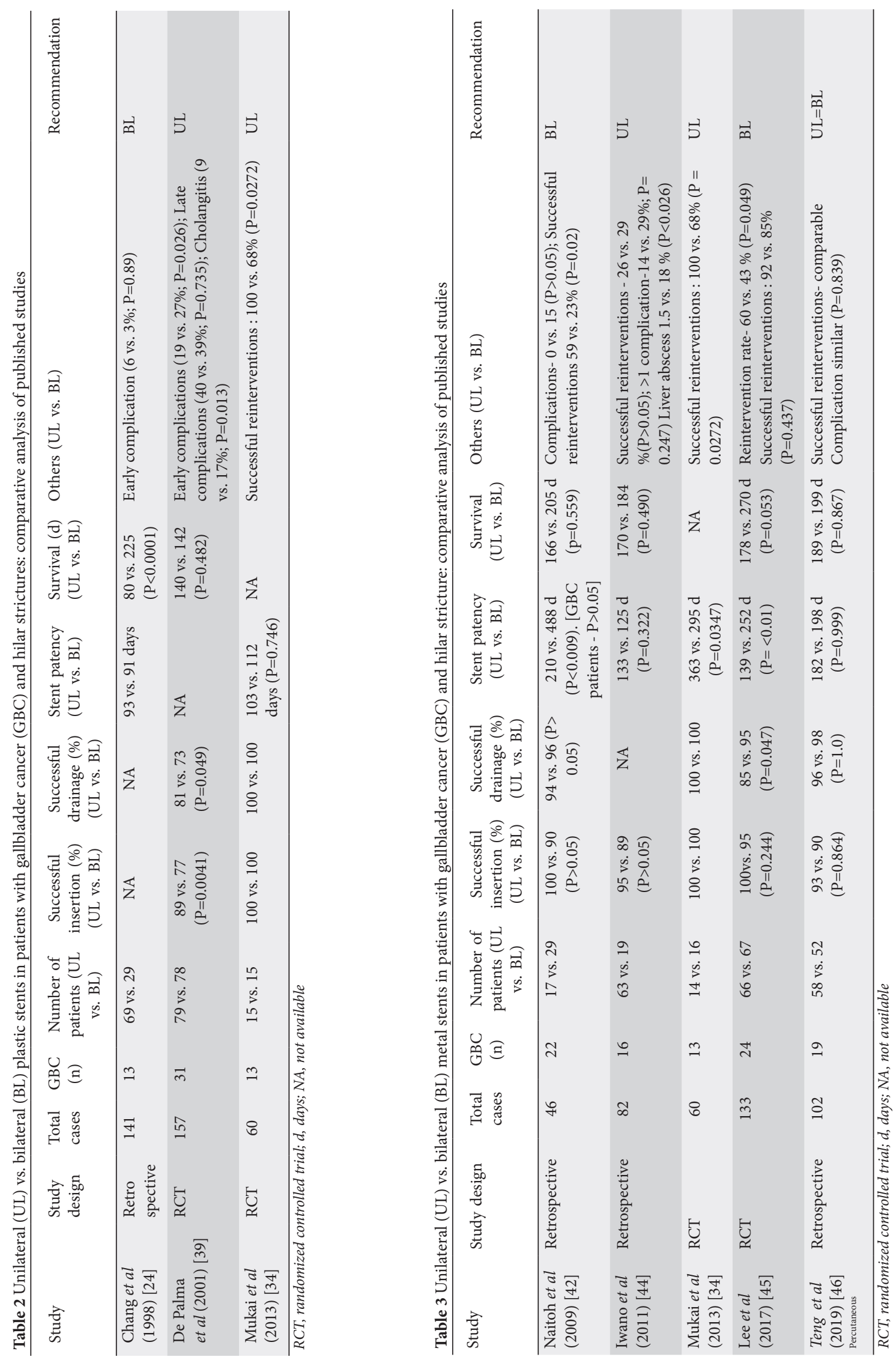
In brief, current evidence revealed unilateral stenting as technically easier for initial placement as well as reinterventions, similarly efficacious and equally safe compared to bilateral drainage in GBC patients with MHS. Therefore, placement of more than one stent is not justified as a routine procedure; however, multiple stenting is warranted if the patient has multiple blocked ducts with cholangitis, or after inadvertent contrast opacification of more than one duct.

\section{Future directions}

The use of drug-eluting biliary stents for the prevention of stent occlusion has been investigated in recent studies [48-51]. Data regarding the clinical benefits of using these drug-eluting stents in human subjects are very limited; paclitaxel is the sole drug evaluated in human subjects with malignant biliary strictures. There was a statistically non-significant trend towards improved patency and survival noted in the drug-eluting stent group. The study did not reveal any harmful effects of the drugeluting stents on human subjects. Therefore, further research and human trials are warranted [50]. Investigations are also required to determine the exact mechanisms of controlleddrug release, systemic absorption from drug-eluting stents and drug-host response interactions.

\section{Concluding remarks}

There is still a lack of definite consensus on the relative merits of plastic vs. metal stents and single vs. multiple stents. Superiority of metal stenting over plastic stent placement in hilar obstruction caused by cholangiocarcinoma has been shown in several studies. However, the existing evidence does not support the superiority of metal stents over plastic stent insertion for endoscopic palliation in patients with hilar strictures due to unresectable GBC. Therefore, plastic stents should be preferred over metal stents for initial endotherapy in patients with inoperable GBC and hilar biliary strictures when cost-effectiveness is taken into consideration. Further multicenter prospective randomized controlled trials are required to determine the appropriate biliary stent type for endoscopic palliation of inoperable GBC with hilar strictures. Current evidence does not favor routine placement of more than one stent; however, multiple stent placement is warranted if the patient has multiple blocked ducts with cholangitis, or after inadvertent contrast opacification of more than one duct.

\section{References}

1. Siegel R, Ma J, Zou Z, Jemal A. Cancer statistics, 2014. CA Cancer J Clin 2014;64:9-29.

2. Singh A, Gelrud A, Agarwal B. Biliary strictures: diagnostic considerations and approach. Gastroenterol Rep (Oxf) 2015;3:22-31.
3. Vij JC, Govil A, Chaudhary A, Gulati R, Mehta S, Ganguli S. Endoscopic biliary endoprosthesis for palliation of gallbladder carcinoma. Gastrointest Endosc 1996;43:121-123.

4. Bray F, Ferlay J, Soerjomataram I, Siegel RL, Torre LA, Jemal A. Global cancer statistics 2018: GLOBOCAN estimates of incidence and mortality worldwide for 36 cancers in 185 countries. CA Cancer J Clin 2018;68:394-424.

5. Rawla P, Sunkara T, Thandra KC, Barsouk A. Epidemiology of gallbladder cancer. Clin Exp Hepatol 2019;5:93-102.

6. Hundal R, Shaffer EA. Gallbladder cancer: epidemiology and outcome. Clin Epidemiol 2014;6:99-109.

7. Shukla VK, Khandelwal C, Roy SK, Vaidya MP. Primary carcinoma of the gall bladder: a review of a 16-year period at the University Hospital. J Surg Oncol 1985;28:32-35.

8. Sheth S, Bedford A, Chopra S. Primary gallbladder cancer: recognition of risk factors and the role of prophylactic cholecystectomy. Am J Gastroenterol 2000;95:1402-1410.

9. Duffy A, Capanu M, Abou-Alfa GK, et al. Gallbladder cancer (GBC): 10-year experience at Memorial Sloan-Kettering Cancer Centre (MSKCC). J Surg Oncol 2008;98:485-489.

10. Flemming JA, Zhang-Salomons J, Nanji S, Booth CM. Increased incidence but improved median overall survival for biliary tract cancers diagnosed in Ontario from 1994 through 2012: A population-based study. Cancer 2016;122:2534-2543.

11. Lindnér P, Holmberg E, Hafström L. Gallbladder cancer - no improvement in survival over time in a Swedish population. Acta Oncol 2018;57:1482-1489.

12. Oertli D, Herzog U, Tondelli P. Primary carcinoma of the gallbladder: operative experience during a 16 year period. Eur J Surg 1993;159:415-420.

13. Dumonceau JM, Tringali A, Papanikolaou IS, et al. Endoscopic biliary stenting: indications, choice of stents, and results: European Society of Gastrointestinal Endoscopy (ESGE) Clinical Guideline Updated October 2017. Endoscopy 2018;50:910-930.

14. Jha AK, Rai VK, Goenka U, et al. Evidence-based approach for endotherapy in pancreaticobiliary malignancies. In: Shrikhande SV, Sirohi B (editors): Modern GI Oncology-E -Book, 1st ed. Elsevier Health Sciences: New Delhi; 2015, pp. 263-277

15. Lee TH, Moon JH, Park SH. Biliary stenting for hilar malignant biliary obstruction. Dig Endosc 2020;32:275-286.

16. Tringali A, Boškoski I, Costamagna G. Endoscopic stenting in hilar cholangiocarcinoma: when, how, and how much to drain? Gastroenterol Res Pract 2019;2019:5161350.

17. Gao DJ, Hu B, Ye X, Wang TT, Wu J. Metal versus plastic stents for unresectable gallbladder cancer with hilar duct obstruction. Dig Endosc 2017;29:97-103.

18. Huibregtse K, Schneider B, Coene PP, Tytgat GN. Endoscopic palliation of jaundice in gallbladder cancer. Surg Endosc 1987;1:143-146.

19. Paik WH, Park YS, Hwang JH, et al. Palliative treatment with selfexpandable metallic stents in patients with advanced type III or IV hilar cholangiocarcinoma: a percutaneous versus endoscopic approach. Gastrointest Endosc 2009;69:55-62.

20. Inamdar S, Slattery E, Bhalla R, Sejpal DV, Trindade AJ. Comparison of adverse events for endoscopic vs percutaneous biliary drainage in the treatment of malignant biliary tract obstruction in an inpatient national cohort. JAMA Oncol 2016;2:112-117.

21. Duan F, Cui L, Bai Y, Li X, Yan J, Liu X. Comparison of efficacy and complications of endoscopic and percutaneous biliary drainage in malignant obstructive jaundice: a systematic review and metaanalysis. Cancer Imaging 2017;17:27.

22. Saluja SS, Gulati M, Garg PK, et al. Endoscopic or percutaneous biliary drainage for gallbladder cancer: a randomized trial and quality of life assessment. Clin Gastroenterol Hepatol 2008;6:944-950.

23. Lee SH, Park JK, Yoon WJ, et al. Optimal biliary drainage for inoperable Klatskin's tumor based on Bismuth type. World $J$ 
Gastroenterol 2007;13:3948-3955.

24. Chang WH, Kortan P, Haber GB. Outcome in patients with bifurcation tumors who undergo unilateral versus bilateral hepatic duct drainage. Gastrointest Endosc 1998;47:354-362.

25. Perdue DG, Freeman ML, DiSario JA, et al; ERCP Outcome Study ERCOST Group. Plastic versus self-expanding metallic stents for malignant hilar biliary obstruction: a prospective multicenter observational cohort study. J Clin Gastroenterol 2008;42:1040-1046.

26. Vienne A, Hobeika E, Gouya H, et al. Prediction of drainage effectiveness during endoscopic stenting of malignant hilar strictures: the role of liver volume assessment. Gastrointest Endosc 2010;72:728-735.

27. Sud R, Puri R, Hussain S, Kumar M, Thawrani A. Air cholangiogram: a new technique for biliary imaging during ERCP. Gastrointest Endosc 2010;72:204-208.

28. Park DH. Endoscopic ultrasound-guided biliary drainage of hilar biliary obstruction. J Hepatobiliary Pancreat Sci 2015;22:664-668.

29. Nakai Y, Kogure H, Isayama H, Koike K. Endoscopic ultrasoundguided biliary drainage for unresectable hilar malignant biliary obstruction. Clin Endosc 2019;52:220-225.

30. Hammarstrom LE. Role of palliative endoscopic drainage in patients with malignant biliary obstruction. Dig Surg 2005;22:295-304.

31. Moss AC, Morris E, Leyden J, MacMathuna P. Malignant distal biliary obstruction: a systematic review and meta-analysis of endoscopic and surgical bypass results. Cancer Treat Rev 2007;33:213-221.

32. Yeoh KG, Zimmerman MJ, Cunningham JT, Cotton PB. Comparative costs of metal versus plastic biliary stent strategies for malignant obstructive jaundice by decision analysis. Gastrointest Endosc 1999;49:466-471.

33. Moss AC, Morris E, Leyden J, MacMathuna P. Do the benefits of metal stents justify the costs? A systematic review and metaanalysis of trials comparing endoscopic stents for malignant biliary obstruction. Eur J Gastroenterol Hepatol 2007;19:1119-1124.

34. Mukai T, Yasuda I, Nakashima M, et al. Metallic stents are more efficacious than plastic stents in unresectable malignant hilar biliary strictures: a randomized controlled trial. $J$ Hepatobiliary Pancreat Sci 2013;20:214-222.

35. Tsuyuguchi T, Itoi T, Takada T, et al; Tokyo Guideline Revision Committee. TG13 indications and techniques for gallbladder drainage in acute cholecystitis (with videos). I Hepatobiliary Pancreat Sci 2013;20:81-88.

36. Miura S, Kanno A, Masamune A, et al. Risk factors for recurrent biliary obstruction following placement of self-expandable metallic stents in patients with malignant perihilar biliary stricture. Endoscopy 2016;48:536-545.

37. Wagner HJ, Knyrim K, Vakil N, Klose KJ. Plastic endoprostheses versus metal stents in the palliative treatment of malignant hilar biliary obstruction. A prospective and randomized trial. Endoscopy 1993;25:213-218.
38. Freeman ML, Overby C. Selective MRCP and CT-targeted drainage of malignant hilar biliary obstruction with self-expanding metallic stents. Gastrointest Endosc 2003;58:41-49.

39. De Palma GD, Galloro G, Siciliano S, Iovino P, Catanzano C. Unilateral versus bilateral endoscopic hepatic duct drainage in patients with malignant hilar biliary obstruction: results of a prospective, randomized, and controlled study. Gastrointest Endosc 2001;53:547-553.

40. Sangchan A, Kongkasame W, Pugkhem A, Jenwitheesuk K, Mairiang P. Efficacy of metal and plastic stents in unresectable complex hilar cholangiocarcinoma: a randomized controlled trial. Gastrointest Endosc 2012;76:93-99.

41. De Palma GD, Pezzullo A, Rega M, et al. Unilateral placement of metallic stents for malignant hilar obstruction: a prospective study. Gastrointest Endosc 2003;58:50-53.

42. Naitoh I, Ohara H, Nakazawa T, et al. Unilateral versus bilateral endoscopic metal stenting for malignant hilar biliary obstruction. $J$ Gastroenterol Hepatol 2009;24:552-557.

43. Boutros C, Gary M, Baldwin K, Somasundar P. Gallbladder cancer: past, present and an uncertain future. Surg Oncol 2012;21:e183-e191.

44. Iwano $\mathrm{H}$, Ryozawa $\mathrm{S}$, Ishigaki $\mathrm{N}$, et al. Unilateral versus bilateral drainage using self-expandable metallic stent for unresectable hilar biliary obstruction. Dig Endosc 2011;23:43-48.

45. Lee TH, Kim TH, Moon JH, et al. Bilateral versus unilateral placement of metal stents for inoperable high-grade malignant hilar biliary strictures: a multicenter, prospective, randomized study (with video). Gastrointest Endosc 2017;86:817-827.

46. Teng F, Xian YT, Lin J et al. Comparison of unilateral with bilateral metal stenting for malignant hilar biliary obstruction. Surg Laparosc Endosc Percutan Tech 2019;29:43-48.

47. Aghaie Meybodi M, Shakoor D, Nanavati J, et al. Unilateral versus bilateral endoscopic stenting in patients with unresectable malignant hilar obstruction: a systematic review and meta-analysis. Endosc Int Open 2020;8:E281-E290.

48. Lee DK, Kim HS, Kim KS, et al. The effect on porcine bile duct of a metallic stent covered with a paclitaxel-incorporated membrane. Gastrointest Endosc 2005;61:296-301.

49. Suk KT, Kim JW, Kim HS, et al. Human application of a metallic stent covered with a paclitaxel-incorporated membrane for malignant biliary obstruction: multicenter pilot study. Gastrointest Endosc 2007;66:798-803.

50. Jang SI, Kim JH, Kim M, et al. Porcine feasibility and safety study of a new paclitaxel-eluting biliary stent with a Pluronic-containing membrane. Endoscopy 2012;44:825-831.

51. Shatzel J, Kim J, Sampath K, et al. Drug eluting biliary stents to decrease stent failure rates: A review of the literature. World $J$ Gastrointest Endosc 2016;8:77-85. 